\title{
Pair-Work Teaching Method and Its Outcome
}

\author{
Shinhong Min
}

\begin{abstract}
The Pair-work teaching method was applied to college students attending nursing departments and was conducted to assess its effectiveness after applying the Pair-work teaching method to the subject of medical terminology that is taught as a basic subject of their majors. The application effect of the Pair-work teaching method was compared with and analyzed whether there was a difference in learning attitude, interest, learning effect, etc. between the experimental group applying the Pair-work and the non-applicable control group. It is analyzed using the SPSS/WIN 18.0 program. Learning attitudes and interests increased only in the experiment group that applied the pair-work. Learning effects were also found to differ from non-pair-work comparators, which were statistically different. This showed that learning medical terms using a pair-work has a positive effect on the learning attitude, interest and learning effects of the target students. Since there have been positive effects in the experiment group that applied the pair-work, it is necessary to study it repeatedly whether teaching methods using the pair-work are developed and applied in other subjects to improve learning outcome.
\end{abstract}

Keywords : Academic interest, Attitude of learning, Learning effect

\section{INTRODUCTION}

In the modern era of the fourth revolution, the need for creative fusion-type talent is required. There are many attempts to cultivate such talent, especially in the education sector. One way to do so is to change from a traditional teacher-centered class to a student-centered one. Teacher-centered education is changing to learner-centered. The subject of education should be student. It should not be a place that only receives knowledge like the existing format. It is a place where I have to be able to express my knowledge and to discover and create new things. This requires learning activities that enable learners to organize and produce results on their own. However, it is not easy for learners to work alone in the field of education [1]. Therefore, student-centered learning activities are needed to solve problems through mutual cooperation among learners. Many teaching methods are being developed that can promote cooperation among learners. They are learning methods that are meaningful not only for themselves but also together. This is because the development of knowledge is not just about memorizing and staying in my knowledge [2]. It is also an element that can be expected to result in better development as a result of collaboration among people. Among them is the Pair-work.

Pair-work is a teaching-learning method that increases

Revised Manuscript Received on July 22, 2019.

Shinhong Min, Department of Nursing, Baekseok University, Cheonan, South Korea.shmin@bu.ac.kr learning effectiveness by enabling interaction among learners. By interacting with learners rather than the way teachers are centered and unilaterally lectured, learners are actively involved in learning on their own. The advantages of these activities can be tailored to match learners' abilities, which can provide learners with an appropriate level of class [3]. It can also increase the ability to practice and listen speaking in the process of talking with a mate. In addition, subjects with different abilities can learn at their own level. So, the emotional atmosphere can also be kept positive. Having the opportunity to speak in a comfortable and acceptable atmosphere reduces the burden and gives you a sense of accomplishment. That also increases confidence in learning [4]. By solving the problem together, not alone, it also reduces the burden of doing it alone. In addition, we can discover advantages and disadvantages of learner, develop learner's advantage through activities with friendship, and complement weaknesses with partner. During the time that we are together, we can care for others and help each other. Therefore, it is the most integrated and efficient form of improving human-to-human relationships.

The subject of medical terminology taught by nursing students is a very important subject that serves as a foundation for the development of major basic skills. Pre-learning of basic medical subjects such as anatomy should be carried out, and it is essential for the psychological training of major subjects to be studied later. It is a basic term that is always used and utilized and increasing knowledge in the subject which will be studied for four years. In addition to this, it is used in clinical practice courses such as hospitals. This is because learner can practice on the understanding of the terms used by teachers. In addition, the necessity and importance of medical terminology courses have been continuously emphasized, as it is essential to fulfill the learning outcomes as a student as well as to perform duties as a nurse when working clinically after graduation [5]. It is needed not only for nurses, but also for communication with other staff members such as doctors, and it is necessary to provide accurate information to patients. In particular, medical terms in basic subjects of anatomy, physiology, and pathology are entirely necessary and used [6], further becoming the center of nursing major.

However, most universities have a medical vocabulary subject as a first-year major. Therefore, due to unfamiliar medical knowledge and lack of understanding of the structure and analysis of terminology, learning difficulties are often complained. There are even extreme consequences such as giving up or failing a subject. However, since these basic medical terminology studies will be used in the clinical field after graduation, it is impossible to give up the need to master basic knowledge in the medical terminology subject [7]. Therefore,

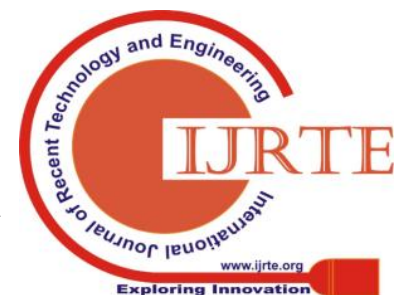


we will need to apply various teaching methods to ease the burden on students. Many attempts have been made for this. In particular, many educational materials have been developed and applied to web-based self-study using smart devices [5][6]. However, there are not many attempts of new teaching methods that can be used during class and improve personal qualities.

According to previous studies, the content experienced by learners in learning through a pair-work was often felt as an attitude toward mutual collaborative learning. As a result, learning efficiency has also increased as it has a positive effect on learning motivation and academic performance. It seems that there is a synergistic effect of learning and cognitive aspects while carrying out cooperative learning in small units. These advantages are even more effective in the process of self-talking and listening to others in learning the language elements such as English learning [8]. It can be easily expressed through the mouth and easily accepted through the ear. Therefore, it would be meaningful for nursing students who first learn medical terminology to experience the learning process through mating activities and examine his effectiveness.

Therefore, in this study, we want to examine the efficiency of teaching methods by applying a pair-work to medical vocabulary classes for nursing students and verifying changes in learning attitude, interest, and effectiveness.

\section{MATERIALS AND METHODS}

\section{A. Research design}

In this study, a similar experimental study applied to the parallax design before and after the non-equivalence control group, the experimental group that received medical term learning classes through the pair-work tried to verify its effect on learning attitude, interest, and learning effects by comparing it with the control group that received traditional medical term learning classes. The study design of this study is illustrated in Table 1. Before the training, both the control group and the experimental group were surveyed. Attitude of learning, Academic interest, as well as general characteristics. After that, Pair-work class was conducted only in the experimental group, and after the same time, the control group and the experimental group again conducted another questionnaire. After the training, the learning effect was added.

Table 1: Research design

\begin{tabular}{|l|l|}
\hline Control group & Experimental group \\
\hline $\mathrm{O}_{1} \mathrm{O}_{2}$ & $\mathrm{O}_{1} \mathrm{X} \mathrm{O}_{2}$ \\
\hline
\end{tabular}

\section{B. Research subject}

The subjects of this study were selected as first-year nursing students attending B University located at A. Through groups using t-test was 1.65 , significant level .05 , power .80 , and the total number of subjects required for the study was 78 and 39 for each group. The subjects of this study were 40 experimenters, 39 comparators and 79 total participants, who met the number of samples, required for the study and understood the purpose of the study and agreed to participate the G-power program, the average difference between the two

in the study.

\section{Data collection}

The data collection was conducted on students who voluntarily agreed to participate in the study among those who took the medical terminology course. The students who agreed to this study were 40 in the experimental group and 39 in the control group. Data collection took place once before the whole class and twice after the whole class. To collect pre-research data, the purpose of the study was described in detail before the first class. In addition, the data collected indicated that the consent forms and questionnaires were separated to be treated anonymously and that the questionnaire was only used for research purposes. Afterwards, they were required to obtain consent for arbitrary research participation in writing, explain the contents of the questionnaire, and submit it by themselves. Post-study data were collected after all classes were finished.

\section{Research hypothesis}

To achieve the purpose of this study, the following assumptions have been established:

1st Statement: The experimental group that has received medical term learning classes through the Pair-work will have higher attitude of learning scores than the control group that has received traditional medical term learning.

2nd Statement: The experimental group that has received medical term learning classes through the Pair-work will have a higher academic interest score than the control group that has received traditional medical term learning.

3rd Statement: The experimental group with medical term learning classes through the Pair-work will have higher learning effect scores than the control group with traditional medical term learning.

\section{E. Research method}

In this study, to assess the attitude of learning including their habits, beliefs, and motivations for learning that had been modified to suit nursing college students [9]. It is a five-point measure of the Likert style, with one "not at all" and five "always" indicating that the higher the score, the better the learning attitude. In this study, Cronbach's $\alpha$ was 0.87 .

An interesting questionnaire was developed by Lee [8]. The content consists of two questions about learning attitude, three questions about class attitude, and five questions about mating activities. The questionnaire had a five-point scale in response to each question, giving the method of grading one point for 'not at all', two points for 'not at all', three points for 'ordinary' and four points for 'so' and five points for 'very so'. This allowed us to see if learning through a pair-work affects not only academic performance, but also a just aspect. The Cronbach's $\alpha$ in this study was 0.88 .

The questionnaire on learning effects used tools that were modified and supplemented in Kim [10]. Each question consists of a five-point Likert scale, and the higher the score, the higher the learning effect. In this study, Cronbach's $\alpha$ was 0.90 . 


\section{F. Research process}

Medical terminology classes are essential and basic knowledge in nursing majors in that they are the basic means of communication for medical and health work. Therefore, it is intended to understand the basic concepts of medical terms such as names and functions of each part of the body, location and associated diseases, measurement for diagnosis, medical equipment, surgery, and so on, and to ensure that the terms are well read.

Class operation was conducted for 15 weeks from August 29 to December 12, 2018, for one hour per week (a total of 15 hours). Classes in each car city consisted of a total of one hour and were conducted in a lecture and a pair-work if necessary, but were operated flexibly by adjusting the time for each group if necessary. The assessment was conducted on final exams and was evaluated by adding a pair-work report, attendance and attitude submitted each time.

A total of five phases of the Pair-work were operated.

Step 1 is 'learning,' and we learned what we need to learn at that time through lectures.

Step 2 is 'problem entry', which requires the issue to be published in a pair-work of evaluation papers to be distributed to other groups to confirm learning.

Step 3, the 'learning checks' phase was required to receive evaluation papers from different groups and write them in a pair-work rather than solving them alone.

Step 4 was required to review the assessment sheet again as a 'scoring' step and proceed as a pair-work in the process of verifying the correct answers.

Step 5, a group of four members gathered to inform them of the scoring results and allow them to review it again. The traditional medical terminology class of the control group was conducted with lecture-style teaching methods and tests centered on teaching materials.

\section{G. Analysis of data}

For the purposes of this study, the data collected used the following methods of analysis using the SPSS18.0 Statistical Program.

First, the general characteristics of the experimental and control groups were obtained in actual numbers and percentages, and homogeneity was analyzed using $\chi 2$-test and Fisher's exact test.

Second, the attitude of learning, academic interest, and learning effect of the experimental and control groups were obtained with mean and standard deviation, and homogeneity was analyzed using the independent t-test.

Third, the difference between the average value of the experimental and control groups on the difference between pre-interference attitude of learning, academic interest, and learning effect was analyzed using the t-test.

\section{RESULTS AND DISCUSSION}

\section{A. Homogeneity test for general characteristics}

Homogeneity verification of the subject's general characteristics has shown that they are all homogeneous <Table 2>. Comparing gender, religion, what you think is your grade, and satisfaction with your nursing major between the experimental and control groups, it turned out to be a homogeneous group.

Table 2: Homogeneity test for general characteristics

\begin{tabular}{|c|c|c|c|c|}
\hline \multirow[t]{2}{*}{ Variable } & \multirow[t]{2}{*}{ Category } & $\begin{array}{l}\text { Experimental } \\
\text { group }(40)\end{array}$ & $\begin{array}{l}\text { Control } \\
\text { group(39) }\end{array}$ & \multirow[t]{2}{*}{$X^{2}$} \\
\hline & & $\mathrm{N}$ & $\mathrm{N}$ & \\
\hline \multirow{2}{*}{ Sex } & Male & 8 & 11 & \multirow{2}{*}{.728} \\
\hline & Female & 32 & 28 & \\
\hline \multirow{2}{*}{ Religion } & $\begin{array}{l}\text { Having } \\
\text { a religion }\end{array}$ & 23 & 21 & \multirow{2}{*}{.107} \\
\hline & $\begin{array}{l}\text { Not having } \\
\text { a religion }\end{array}$ & 17 & 18 & \\
\hline \multirow{3}{*}{$\begin{array}{l}\text { Academic } \\
\text { performanc } \\
\text { e }\end{array}$} & High grade & 12 & 14 & \multirow{3}{*}{1.068} \\
\hline & $\begin{array}{l}\text { Average } \\
\text { in grades }\end{array}$ & 22 & 17 & \\
\hline & Poor grade & 6 & 8 & \\
\hline \multirow{3}{*}{$\begin{array}{l}\text { Satisfactio } \\
\mathrm{n} \quad \text { with } \\
\text { Nursing } \\
\text { major }\end{array}$} & Satisfaction & 33 & 30 & \multirow{3}{*}{.416} \\
\hline & $\begin{array}{l}\text { In ordinary } \\
\text { circumstances }\end{array}$ & 6 & 8 & \\
\hline & Unsatisfactory & 1 & 1 & \\
\hline
\end{tabular}

\section{B. Homogeneity test for Attitude of learning, Academic} interest

A preliminary homogeneity test of the subject's attitude of learning and academic interest was Table 3. The attitude of learning in the experimental group was $52.58 \pm 6.40$ and the academic interest was $34.60 \pm 3.02$. The attitude of learning in the control group was 53.21 \pm 5.96 , academic interest was $34.33 \pm 4.29$. There was no significant difference between the experimental and control groups, indicating that they were homogeneous ( $\mathrm{p}>.05)$.

Table 3: Homogeneity test for Self-efficacy, self-directed learning

\begin{tabular}{|l|l|l|l|l|}
\hline \multirow{2}{*}{ Category } & $\begin{array}{l}\text { Experimental } \\
\text { group }\end{array}$ & Control group & \multirow{2}{*}{$\mathrm{t}$} & $\mathrm{p}$ \\
\cline { 2 - 3 } & $\mathrm{M} \pm \mathrm{SD}$ & $\mathrm{M} \pm \mathrm{SD}$ & & \\
\hline $\begin{array}{l}\text { Attitude of } \\
\text { learning }\end{array}$ & $52.58 \pm 6.405$ & $53.21 \pm 5.966$ & -0.452 & 0.652 \\
\hline $\begin{array}{l}\text { Academic } \\
\text { interest }\end{array}$ & $34.60 \pm 3.028$ & $34.33 \pm 4.294$ & 0.318 & 0.751 \\
\hline
\end{tabular}

\section{Hypothesis test 1}

"The 1st hypothesis: The experimental group that has received medical term learning classes through the Pair-work will have higher learning attitude scores compared to the control group that has received traditional medical term learning."

The test group's post-learning attitude score was 61.80 points, up 9.22 points from the pre-inspection, while the control group was 54.90 points, up 1.69 points from the pre-inspection, indicating a significant improvement in learning attitude over the control group $(t=9.714, p<.001) 1 \mathrm{st}$ hypothesis' was supported <Table $4>$. 
Table 4: Hypothesis test 1

\begin{tabular}{|c|c|c|c|c|c|}
\hline & & $\begin{array}{l}\text { pre-experime } \\
\text { nt }\end{array}$ & $\begin{array}{l}\text { post- } \\
\text { experiment }\end{array}$ & \multirow[t]{2}{*}{$\mathrm{t}$} & \multirow[t]{2}{*}{$\mathrm{p}$} \\
\hline & & $\mathrm{M} \pm \mathrm{SD}$ & $\mathrm{M} \pm \mathrm{SD}$ & & \\
\hline \multirow{2}{*}{$\begin{array}{l}\text { Attitude } \\
\text { of } \\
\text { learning }\end{array}$} & $\begin{array}{l}\text { Experim } \\
\text { ental } \\
\text { group }\end{array}$ & $52.58 \pm 6.405$ & $61.80 \pm 8.093$ & -9.714 & 0.000 \\
\hline & $\begin{array}{l}\text { Control } \\
\text { group }\end{array}$ & $53.21 \pm 5.966$ & $54.90 \pm 5.995$ & -1.508 & 0.140 \\
\hline
\end{tabular}

\section{Hypothesis test 2}

"The 2nd hypothesis: pair - work a group with medical term for learning lessons by learning the traditional medical term than academic interest to controls, will also be the highest single score."

The academic level of interest group from 34.6040 .85 to 6.25 points, control, improved from 34.3335 .79 to 1.46 points, improved more, than in the control group. Been referred to as to improve $(\mathrm{t},=-6.493, \mathrm{p}<.001)$ ' 2 nd hypothesis' was supported $<$ Table $5>$.

Table 5: Hypothesis test 2

\begin{tabular}{|l|l|l|l|l|l|}
\hline \multirow{2}{*}{} & & $\begin{array}{l}\text { pre-experim } \\
\text { ent }\end{array}$ & $\begin{array}{l}\text { post- } \\
\text { experiment }\end{array}$ & \multirow{2}{*}{$\mathrm{t}$} & $\mathrm{p}$ \\
\cline { 3 - 5 } & $\mathrm{M} \pm \mathrm{SD}$ & $\mathrm{M} \pm \mathrm{SD}$ & \\
\hline \multirow{2}{*}{$\begin{array}{l}\text { Academ } \\
\text { ic } \\
\text { interest }\end{array}$} & $\begin{array}{l}\text { Experim } \\
\text { ental } \\
\text { group }\end{array}$ & $34.60 \pm 3.028$ & $40.85 \pm 5.102$ & -6.493 & 0.000 \\
\cline { 2 - 5 } & $\begin{array}{l}\text { Control } \\
\text { group }\end{array}$ & $34.33 \pm 4.294$ & $35.79 \pm 4.318$ & -1.856 & 0.071 \\
\hline
\end{tabular}

\section{E. Hypothesis test 3}

"The 3rd hypothesis: The experimental group that has received medical term learning classes through the Pair-work will have higher learning effect scores than the control group that has received traditional medical term learning."

The learning effect level was 34.68 points after the Pair-work class, and the control group was 31.92 points, indicating that the learning effect level was significantly higher than that of the control group $(\mathrm{t}=5.859, \mathrm{p}<0.001)$ $<$ Table 6>.

Table 6: Hypothesis test 3

\begin{tabular}{|l|l|l|l|l|}
\hline & & post-experiment & \multirow{2}{*}{$\mathrm{t}$} & $\mathrm{p}$ \\
\cline { 3 - 5 } & & $\mathrm{M} \pm \mathrm{SD}$ & & \\
\hline \multirow{2}{*}{$\begin{array}{l}\text { Learning } \\
\text { effect }\end{array}$} & Experimental group & $34.68 \pm 2.841$ & \multirow{2}{*}{5.859} & 0.000 \\
\cline { 2 - 3 } & Control group & $31.92 \pm 2.851$ & & \\
\hline
\end{tabular}

\section{CONCLUSION}

The study was attempted to increase the efficiency of nursing students' medical terminology learning. Pair work was applied in the course of medical terminology. The effects on the Attitude of learning, Academic interest and Learning effect were then verified compared to traditional lecture classes.

The results of the study are as follows. The experimental group with pair work improved by significantly different preand post-education learning attitudes, interests, and learning effects compared to the control group that conducted the lecture class. This means that by increasing the time to recall what you learned with your partner in class and by encouraging learner-oriented classes to interact autonomously, it has had a significant impact on the cognitive area of learning enhancement, as well as on defining areas such as interest in class and motivation. It has also shown a positive effect on building confidence by encouraging voluntary student participation, cooperating and improving their ability to solve it.

Not only the statistical results but also the positive effects of listening to the students' personal opinions were also obtained. It would have been difficult if learner had to talk in front of all the students. It was a story that learner was able to talk with partner next to learner, so learner could speak the words out of mouth easily. There was a story that learner could have more confidence in speaking so many times. In addition, there was also a story that during the time, it was possible to amplify the effect even more in the course of preparing or preparing for better appearance.

In education conducted within the nation's nursing department, there are few cases in which pair work classes are implemented and few studies have examined the effects. Therefore, we will need to develop and apply a peer work class suitable for the characteristics of each subject in other subjects and then repeat the research to verify its effectiveness.

\section{ACKNOWLEDGMENT}

This research was supported by Baekseok University in Korea.

\section{REFERENCES}

1. J. H. Bae, "(A) study on the development of problem based learning module for nursing clinical practice" Master's thesis, Busan National University; 2005

2. M. A. Park, "Nurses and Nursing Students' Recognition of Good Instruction" Master's thesis, Ewha Womans University, 2018.

3. M. Long, P. A. Porter, "Group Work, Interlanguage Talk, and Second Language Acquisition” TESOL Quarterly, 19(2), 1985, pp. 207-228.

4. Y. S. Jang, "Effects of Pair/Group Work on English Vocabulary Acquisition" Journal of The Korea Contents Society, 15(7), 2015, pp. 629-642,

5. B. K. Lee, "Development of a Medical Terminology Learning App for Smart Education" Journal of Digital Contents Society, 18(1), 2017, pp. 25-33.

6. K. S. Shin, M. K. Jo, "The Knowledge, Need, and Usage of Medical Terminology in Clinical Nursing Practice" Journal of Korean Society of Biological Nursing Science, 16(4), 2014, pp. 276-283.

7. M. H. Jeong, "A Web-based Contents Design for Teaching-Learning Medical Terminology and Its Effects" Master's thesis, Woosuk University, 2007.

8. S. Y. Hwang, "Effects of Problem-based Learning on the Knowledge Achievement, Critical Thinking Ability, Attitude and Motivation toward Learning of Nursing Students" Ph.D Thesis, Chonnam National University, 2003.

9. J. E. Lee, "Effect of paired work in English reading class" Master's thesis, Ajou University, 2007.

10. H. K. Kim, "Enhancing Self-directed Learning Ability in English Using Web sites" Ph.D Thesis, Woosuk University, 2003

\section{AUTHORS PROFILE}

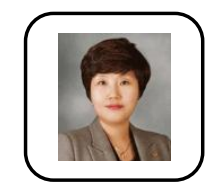

Shinhong Min, Ph.D., RN

Associate Professor of Nursing at Baekseok University Education details: Adult healthy Nursing

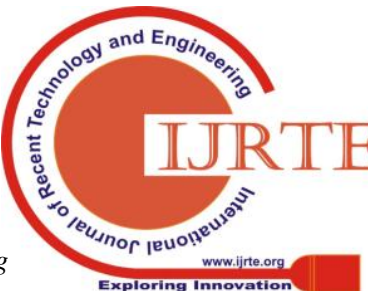

